\title{
Phytochemical Determination and In Vitro Antimicrobial Activity of Crude Ethanolic Extract of Stem Bark of Boswellia dalzielii
}

\author{
Baha'uddeen Salisu Dandashire ${ }^{1}$, Abdulkadir Magaji Magashi ${ }^{2}$ Bashir Abdulkadir $^{3}$ \\ ${ }^{1,3}$ Department of Microbiology, Faculty of Natural and Applied Sciences, Umaru Musa Yar'adua University, Katsina, Katsina State, \\ Nigeria \\ ${ }^{2}$ Department of Microbiology, Faculty of Science, Bayero University, Kano, Nigeria
}

\begin{abstract}
Background: Boswellia dalzielii is a medicinal plant widely used in the traditional treatments of Rheumatism, Septic sores, venereal diseases and gastrointestinal ailments. However, the scientific evaluations of the ethanopharmacological claims of the plant have not been adequately resolved. Aim: To carryout automated phytochemical screening and determination of the in vitro antimicrobial activity of the crude ethanolic stem bark extract of $B$. dalzielii on some common pathogenic microorganisms which included Staphylococcus aureus, Streptococcus pyogenes, Enterococcus faecalis, Escherichia coli, Pseudomonas aeruginosa, Klebsiella pneumoniae, Proteus mirabilis, Salmonella typhi and Candida albicans. Methods: Fifty grams (50g) of the dried powder of the stem bark of the plant was extracted exhaustively in $500 \mathrm{ml}$ of $95 \%$ ethanol by percolation method for two weeks. Phytochemical screening of the extract was performed using High Performance Liquid Chromatography (HPLC), Fourier Transformed Infrared Spectroscopy (FTIR) and Gas Chromatography-Mass Spectrometry (GCMS) after which its antimicrobial activity was evaluated by agar well diffusion method. The minimum inhibitory concentrations (MICs) and minimum bactericidal concentration (MBC)/ Minimum Fungicidal concentration (MFC) were also determined using the broth micro-tube dilution technique. Results: The HPLC analysis revealed the presence of 8 components with major ones at peaks $3,4,5$ and 2 with peak areas of $31.52 \%, 21.96 \%$, 17.23\% and 16.21\% respectively; the FT-IR spectroscopy revealed 11 functional groups which included $1^{\circ}, 2^{\circ}$ amines and amides, alkanes, alkenes, alkynes, alkyl halides, aromatics and aliphatic amines; while the GCMS analysis revealed 13 compounds and the major ones were n-Hexadecanoic acid (23.54\%), Oxacyclotetradecan-2-one (20.33\%), Pelargic acid (16.83\%), n-Eicosanol (13.51\%) and Ethyl striate (10.05\%). Several studies reported that these compounds have antimicrobial, anticancer and anti-oxidant activities except n-Eicosanol and Ethyl steriate which are highly toxic. The susceptibility test showed that the extract was active against all the test isolates with higher zones of inhibition of $21 \pm 0.00 \mathrm{~mm}$ for $C$. albicans and $S$. typhi, $20 \pm 0.80 \mathrm{~mm}$ for $S$. aureus, and $19 \pm 0.50 \mathrm{~mm}$ for $\mathrm{K}$. Pneumoniae, $18 \pm 0.80 \mathrm{~mm}$ for $E$. coli and $18 \pm 0.80 \mathrm{~mm}$ for $P$. aeruginosa at $50 \mathrm{mg} / \mathrm{ml}$ concentration each. Resistance was only observed at $2.5 \mathrm{mg} / \mathrm{ml}$ concentration for $S$. pyogenes. Similarly, lowest MIC values of $3.12 \mathrm{mg} / \mathrm{ml}$ were obtained for C. albicans and $S$. typhi, $6.25 \mathrm{mg} / \mathrm{ml}$ for $S$. aureus, $12.5 \mathrm{mg} / \mathrm{ml}$ for $\mathrm{K}$. Pneumoniae, E. faecalis and P.mirabilis, 25mg/ml for E.coli and S. pyogenes and the highest MIC of 50mg/ml for P. aeruginosa. The $M B C / M F C$ values did not exceed the corresponding MIC values by more than a factor of 2 . Conclusion: Although the stem bark of B. dalzielii showed strong antibacterial and antifungal activity and contained many antimicrobially active compounds, it also contained potentially toxic components and hence adequate toxicological data is needed to validate the safety of the stem bark of this plant for consumption.
\end{abstract}

Keywords: Antimicrobial, Chromatography, Ethanolic, Extract, Fungicidal and Phytochemical

\section{Introduction}

The uncontrolled use of antibiotics is thought to have spurred evolutionary adaptations that enable microorganisms to survive most of the powerful drugs, thereby encouraging the proliferation of drug resistance among pathogens and normal flora (Schwarz et al., 2001; Rantala et al, 2004; Cabello, 2006; Sande-Bruinsma et al., 2008; Franco, et al., 2009; Susanne and Karen, 2011; Da Costa, et al., 2013; MFMER, 2014). Transfer of R-factor to other bacteria increases the probability of therapeutic failure (Susanne and Karen, 2011; Händel et al., 2015; Hsiao-Han, et al., 2015). Infections from resistant bacteria are now a worldwide problem as some pathogens have even become resistant to multiple types or classes of antimicrobials (CDC, 2013). Consequently, as many existing antimicrobials are becoming less effective, the rapid spread of multi-drug resistant (MDR) bacteria will results to reaching a point where by common everyday infections or diseases could not be treated or prevented (Nemesisbio, 2017). This loss of effective antibiotics will definitely devitalize the means of fighting infectious diseases and management of infectious complications common in patients with impaired immune system, for which the ability to treat secondary infections is pivotal (CDC, 2013).

It has been shown that the choice of drugs in the treatment of many infections is quite narrow today due to the wide scale resistance that the common pathogens show to drugs which have been used previously (Ahmad et al., 2012). In fact, many drugs which are considered as effective against many pathogens are now rarely prescribed as empirical therapy in areas where resistance rate to those antibiotics is high (Rawat and Umesh, 2010; Shalini et al., 2011). Thus, the process of developing new antimicrobials and new technologies to allow quicker diagnosis and facilitate targeted treatment must be accelerated (BBC, 2014).

The above problems necessitate the urgent need to carry out more research works with a view to finding some newer, safer, and more effective agents that can be used for effective management of infections. Medicinal plants have been the nature's major source of medicines and the search for them have led to the discovery of many compounds with

Volume 6 Issue 12, December 2017 


\section{International Journal of Science and Research (IJSR) \\ ISSN (Online): 2319-7064}

Index Copernicus Value (2016): 79.57 | Impact Factor (2015): 6.391

antimicrobial potential (Sermakkani et al., 2012). The choice of $B$. dalzielii in this research was due to the high traditional use of the plant, especially the stem bark, in treating many ailments. Although some research works were previously conducted on the stem bark of the plant, little or no work has been done so far using advanced automated techniques to determine the identity of the phytochemical components present in the ethanolic extract of the stem bark of the plant, hence the need to embark on the research and its contribution to knowledge.

\section{Materials and Methods}

\section{Collection, Identification and Authentication of the Plant Material}

The stem bark of the plant, B. dalzielii, was collected from the bushes around Kafur Local Government area of Katsina State, Nigeria in the month of February, 2015. It was identified and authenticated at the Herbarium of the Department of Plant Biology, Bayero University, Kano where a voucher specimen was deposited. The stem bark was washed under running tap water, air- dried at room temperature in the laboratory until brittle, and then pulverized to fine powder and stored in airtight glass containers at room temperature in the dark until use as according to technique of Sunday et al. (2010) and Salisu et al., (2017).

\section{Extraction of the Crude Extract}

The powdered sample of the stem bark was extracted following the method of Salisu et al., (2017).

Fifty grams $(50 \mathrm{~g})$ of the dried powder of the stem bark of the plant was weighed into a glass container and extracted exhaustively in $500 \mathrm{ml}$ of $95 \%$ ethanol by percolation method for two weeks during which the sealed bottle was undergoing vigorous shaking at regular intervals. The mixture obtained was filtered through muslin cloth and then re-filtered by passing through Number 1 Whattman's filter paper. The filtrate was concentrated by complete evaporation of the solvent at room temperature. The extract was subsequently transferred into clean sterile airtight glass container and stored in the refrigerator at $4^{\circ} \mathrm{C}$ before downstream application.

\section{Automated Phytochemical Screening of the Extract}

\section{High Performance Liquid Chromatography Analysis (HPLC)}

The High Performance Liquid Chromatography Analysis (HPLC) was carried out to determine the number of phytochemicals and their percentages in the extract as follows.

Sample Preparation: Stock solution of the extract was prepared in HPLC grade methanol at a concentration of $100 \mu \mathrm{gmL}^{-1}$ and stored in a refrigerator until use. The sample was filtered through Whattman No.1 filter paper before undertaking HPLC analysis.

Analysis: HPLC was carried out on the extract as according to Salisu et al., (2017). The analysis was performed using an Agilent Zorbax column (Xdb-C18 Type MG $5 \mu \mathrm{m}, 4.6 \times 250$ $\mathrm{mm})$. The detection wavelength was $254 \mathrm{~nm}$. The analysis was carried out at a constant flow rate of $1.2 \mathrm{~mL} / \mathrm{min}$ all throughout, with an average pressure of about 2100 psi. Prior to injection of the sample into the system, the mobile phase was pumped through the column for at least 30 minutes in order to warm up the instrument and achieved equilibration of the column. Elution was carried out with $\mathrm{CH}$ $\mathrm{CN}-\mathrm{H}$ O. The injection volume was $100 \mu \mathrm{ml}$. All chromatographic data were recorded and processed using autochro-3000 software.

\section{Fourier Transform Infrared Spectrophotometer (FTIR) Analysis}

Fourier Transform Infrared Spectrophotometer (FTIR) Analysis was carried out on the extract using Shimadzu, Japan, FT-IR spectrometer as described by Salisu et al., (2017). A $0.1 \mathrm{ml}$ of the sample was dropped into an Arsenic selenide $\left(\mathrm{As}_{2} \mathrm{Se}_{3}\right)$ aperture plate of $0.1 \mathrm{~mm}$ thick and loaded in the FTIR spectroscope. The sample was scanned from 650 to $4000 \mathrm{~cm}^{-1}$ for 16 times to increase the signal to noise ratio. FT-IR spectra were recorded in the absorption range between 650 and 4000 wave number per centimetre at a resolution of $4 \mathrm{~cm}^{-1}$. The types of chemical bonds/functional groups present in the extract were identified by interpreting the infrared absorption spectrum using IR spectra Table.

\section{Gas Chromatography- Mass Spectrometry Analysis (GC-MS)}

GC-MS of the extract was carried out to further confirm the identity of the phytocomponents following the technique of Salisu et al., (2017). The analysis was carried out using GCMS ( Model: QP 2010 series, Shimadzu, Japan) equipped with a VF-5ms fused silica capillary column of $30 \mathrm{~m}$ length, $0.25 \mathrm{~mm}$ diameter and $0.25 \mu \mathrm{m}$ film thickness. The column oven temperature was programmed from $70^{\circ} \mathrm{C}$ to $200^{\circ} \mathrm{C}$ for $2^{0} \mathrm{C} \mathrm{min}^{-1}$. Ionization of the sample components was performed in electron impact mode (EI, $70 \mathrm{eV}$ ). The temperature of the injector was fixed to $200.00^{\circ} \mathrm{C}$ and one of the detectors to $250^{\circ} \mathrm{C}$. Helium $(99.9995 \%$ purity) was the carrier gas fixed with a flow rate of $1.80 \mathrm{ml} \mathrm{min}^{-1}$. The mass ranges from $40-1000 \mathrm{~m} / \mathrm{z}$ was scanned at a rate of 3.0 scans/s. $1.0 \mu \mathrm{l}$ of the extract was injected with a Hamilton syringe to the GM-MS manually for total ion chromatographic analysis in split injection technique. Total running time of GC-MS was $35 \mathrm{~min}$.

Identification of the Constituents: Identity of the various compounds detected by the GC-MS from the extract was carried out based on the comparison of their retention indices and mass spectra fragmentation patterns with those stored in the computer library (i.e the spectrum of the unknown component was compared with the spectrum of the known components stored in the NIST Library) and the interpretation of the mass spectrum GC-MS was conducted using data base of National Institute of Standard Technology (NIST08s), Wiley Registry of Mass Spectral data New York (Wiley 8) and Fatty Acid Methyl Esters Library, version 1.0 (FAME Library) sources were used for matching the detected compounds in the Extract. The molecular weights, molecular formulae and the number of hits used to identify the name of the compounds from NIST and Wiley spectra were also recorded.

\section{Volume 6 Issue 12, December 2017}




\section{International Journal of Science and Research (IJSR) \\ ISSN (Online): 2319-7064}

Index Copernicus Value (2016): 79.57 | Impact Factor (2015): 6.391

Quantification of the Constituents: The relative percentage of each constituent in the extract was expressed as percentage with peak area normalization.

\section{Bioassay Studies}

Test Organisms: The clinical isolates of bacteria and the fungus used for this study were obtained from Aminu Kano Teaching Hospital, Kano (AKTH). These organisms are as follows: Staphylococcus aureus, Streptocoocus pyogenes, Enterococcus faecalis, Escherichia coli, Klebsiella pneumoniae, Proteus mirabilis, Pseudomonas aeruginosa, Salmonella typhi and Candida albicans.

Storage and Maintenance of Cultures: The pure cultures of the bacteria were streaked on to Nutrient Agar slants and then incubated at $37^{\circ} \mathrm{C}$ for 24 hours, while the fungus was streaked on to Sabroud Dextrose Agar slant and incubated at room temperature of $25^{\circ} \mathrm{C}-28^{\circ} \mathrm{C}$ for 48 hours. The cultures were stored in the refrigerator at $4^{\circ} \mathrm{C}$ until needed for subsequent use.

\section{Standardization of Inocula}

The inocula of the test organisms were standardized using $0.5 \mathrm{McF}$ arland's turbidity standard. Approximately $99.5 \mathrm{ml}$ of $1 \% \mathrm{BaCl}_{2}$ was added to $0.5 \mathrm{ml}$ of $1 \% \mathrm{H}_{2} \mathrm{SO}_{4}$ in order to obtain $100 \mathrm{ml}$ of $\mathrm{BaSO}_{4}$ which corresponded to 0.5 McFarland's turbidity standard equivalent to $1.0 \mathrm{X} 10^{8}$ $\mathrm{cfu} / \mathrm{ml}$ population for bacterial isolates. Bacterial colonies from the 18hours overnight cultures were used to make direct suspension of each bacterial isolate in separate test tubes containing $1 \mathrm{ml}$ of sterile physiological saline. The suspensions were adjusted to match the 0.5 McFarland turbidity standard, using saline and a vortex mixer. Similarly, the fungal culture was standardized according to the methods of Murugan et al. (2007) by dissolving a loopful of the spore suspension into $10 \mathrm{ml}$ of $20 \%$ tween 80 solution to obtain $6.0 \mathrm{X}$ $10^{5} \mathrm{cfu} / \mathrm{ml}$.

\section{Antimicrobial Susceptibility Test \\ The antimicrobial activity of the extract was tested using agar well diffusion method adopted from CILS (1998). Müeller Hinton agar plates were prepared for Staphylococcus aureus, Escherichia coli, Klebsiella pneumoniae, Proteus mirabilis, Pseudomonas aeruginosa and Salmonella typhi; Müeller Hinton Blood agar plates for Streptococcus pyogenes, Enterococcus faecalis; and SDA plates for Candida albicans.}

The plates were separately inoculated with the suspension of the standardized cultures using sterile swabs. In each case, the sterile swab was submerged in the suspension, lifted out, and the excess fluid was removed by pressing and rotating the swab against the wall of the test tube. The swab was then used to inoculate the entire surface of the plate three times, rotating the plate 60 degrees between each inoculation. Each inoculum was allowed to dry for few minutes.

Five wells of $6 \mathrm{~mm}$ diameter were made in each plate using $6 \mathrm{~mm}$ sterile cork borer. The wells were filled with $0.1 \mathrm{ml}$ of diluted concentrations $(50 \mathrm{mg} / \mathrm{ml}, 25 \mathrm{mg} / \mathrm{ml}, \quad 10 \mathrm{mg} / \mathrm{ml}$, $5 \mathrm{mg} / \mathrm{ml}$ and $2.5 \mathrm{mg} / \mathrm{ml}$ ) of the extract with the aid of sterile pipettes per well. Sterile distilled water and $10 \mu \mathrm{g} / \mathrm{ml}$ of
Ciprofloxacin were used in separate plates for each organism to serve as negative and positive controls respectively. Diameters of the zones of inhibition were measured with a transparent ruler and the result was recorded in millimetres after incubating the plates at $37^{\circ} \mathrm{C}$ for 24 hours (bacteria) and $25^{\circ} \mathrm{C}$ for 48 hours (fungus). The plates were replicated in triplicates and the means and standard errors of the zones of inhibitions for each organism at each concentration of each extract were calculated and recorded accordingly as described by Baha'uddeen et al. (2017).

\section{Determination of Minimum Inhibitory Concentration (MIC)}

The MIC of the extract was determined by standard two-fold micro dilution method adopted from CILS, (1998). A stock solution of the extract was serially diluted in nine test tubes containing $5 \mathrm{mls}$ double strength Mueller Hinton broth each (for bacteria) or SDA broth (for fungus) and labelled 1, 2, 3, $4, \mathrm{~S}, 6,7,8$, and 9 ; to obtain a concentration of $100,50,25$, $12.5,6.25,3.12,1.56$ and $0.78 \mathrm{mg} / \mathrm{ml}$. Tube 9 was the control and had no drug or extract. $0.1 \mathrm{ml}$ of the standardized inocula was inoculated in the separate tubes 1-9 for each organism. The various test tube racks were kept at $37^{\circ} \mathrm{C}$ for an overnight incubation (bacteria) and $25^{\circ} \mathrm{C}$ for 48 hours (fungus). Then, the MICs were recorded as the lowest concentration of the extract inhibiting the visible growth of test organisms. This was determined by comparing the tubes with the control against a source of light with white back ground and some contrasting black lines.

\section{Determination of Minimum Bactericidal Concentration (MBC) and the Minimum Fungicidal Concentration (MFC)}

The MBCs and the MFCs were determined using the methods of Hugo and Russel (1994). The tubes in each set, which did not show any growth during the MIC and MFCs determination, were used. A loop full of the content from each of the required MIC and MFC tubes was streaked unto new nutrient agar plates for the bacteria and SDA plates for the fungus. The plates were incubated for another 24 hours at $37^{\circ} \mathrm{C}$ (bacteria) and for 48 hours at room temperature of $25^{\circ} \mathrm{C}$ (fungus). After the incubation period, the plates were examined for growth or otherwise. The MBCs and the MFCs of the extract were recorded as the smallest concentration of the extract that is capable of killing the entire organism present in the specific inoculum size of test organism.

\section{Results}

\section{A. Physical Characteristics and the Percentage Yield of the Extract}

The physical characteristics and the percentage yield of the extract are shown in (Table 1). Both the filtrate and residue appeared reddish in colour, whereas the extract appeared light red in colour with gummy and solid textures. The percentage yield of the extract was $13.4 \%$ of the total sample extracted. The extract was found to be soluble in $10 \%$ dimethyl sulphoxide (DMSO) and partially soluble in distilled water. 


\title{
International Journal of Science and Research (IJSR) \\ ISSN (Online): 2319-7064 \\ Index Copernicus Value (2016): 79.57 | Impact Factor (2015): 6.391
}

Table 1: Physical Characteristics and the Percentage Yield of the Extract

\begin{tabular}{|c|c|c|}
\hline S/N & Parameters & Observation/Result \\
\hline 1 & $\begin{array}{c}\text { Weight of the stem bark Powder } \\
\text { Extracted }\end{array}$ & $500 \mathrm{~g}$ \\
\hline 2 & Colour of the Filtrate & Red \\
\hline 3 & Colour and Texture of the Extract & Red and Gummy \\
\hline 4 & Weight of the extract & $67.0 \mathrm{~g}$ \\
\hline 5 & $\%$ Yield & $13.4 \%$ \\
\hline
\end{tabular}

\section{B. Phytochemical Screening}

Medicinal plants are generally indispensable at the present age because, being the major sources of many pharmacologically active compounds; they continue to play a dominant role in the maintenance of human health.

The HPLC chromatogram of the crude Ethanolic extract of $B$. dalzielii stem bark showing the HPLC finger prints of the various compounds present are given in (Figure 1). The result showed that the extract contained 8 phytocomponents at different peaks of the chromatogram. Table 2 on the other hand, showed the detailed tabulation of the HPLC analysis of the extract. From the Table, the major constituents were at peaks 3 (peak area $31.52 \%$ ), Peak 4 (peak area 21.96\%), peak 5 (peak area 17.23\%) and peak 2 ( peak area 16.21\%). While the rest constitute less than $10 \%$ by peak area of the extract.

Table 2: Phytochemical Components of the Ethanolic Extract of the Stem Bark of Boswellia dalzialii Obtained by HPLC Analysis

\begin{tabular}{|c|c|c|}
\hline Peak Number & Retention Time (min) & Area (\%) \\
\hline 1 & 2.144 & 4.92 \\
\hline 2 & 2.413 & 16.21 \\
\hline 3 & 5.868 & 31.52 \\
\hline 4 & 6.073 & 21.96 \\
\hline 5 & 6.266 & 17.23 \\
\hline 6 & 6.593 & 6.25 \\
\hline 7 & 6.824 & 0.65 \\
\hline 8 & 12.728 & 1.23 \\
\hline
\end{tabular}



Figure 1: HPLC Chromatogram of the Crude Ethanolic Extract of Boswellia dalzielii

Similarly, the FTIR spectra of the extract showing the various types of chemical bonds/functional groups were given in (Figure 2). On the other hand, Table 3, showed the interpretation of the FTIR spectral compounds in the extract. From the table, 11 functional groups were identified in the extract including $1^{\circ}, 2^{\circ}$ amines and amides, alkanes, alkenes,

\section{Volume 6 Issue 12, December 2017}

\author{
www.ijsr.net
}




\section{International Journal of Science and Research (IJSR) \\ ISSN (Online): 2319-7064 \\ Index Copernicus Value (2016): 79.57 | Impact Factor (2015): 6.391}

alkynes, alkyl halides, aromatics and aliphatic amines (Table

$3)$.

Table 3: Various Functional Groups/Chemical Bonds Present in the Ethanolic Extract of Stem Bark of B. dalzielii Identified by FTIR Analysis.

\begin{tabular}{|c|c|c|c|c|c|}
\hline Peak No. & $\begin{array}{c}\text { Wave Length } \\
\left(\mathrm{cm}^{-}\right)\end{array}$ & $\begin{array}{c}\text { Transmit- } \\
\text { tance }(\mathrm{t})\end{array}$ & Peak Shape & Type of Bond Identified & Functional Group \\
\hline 1 & 3319 & 66.919 & Curve & N-H stretch & $1^{\circ}, 2^{\circ}$ amines, amides \\
\hline 2 & 2944 & 76.826 & Sharp & C-H stretch & Alkanes \\
\hline 3 & 2833 & 77.555 & Sharp & C-H stretch & Alkanes \\
\hline 4 & 2123 & 99.941 & Weak & - C =-C- stretch & Alkynes \\
\hline 5 & 1655 & 95.626 & Narrow & - C=C- stretch & Alkenes \\
\hline 6 & 1451 & 82.221 & Sharp & C-C stretch (in-ring) & Aromatics \\
\hline 7 & 1413 & 83.512 & Narrow & C-C stretch (in-ring) & Aromatics \\
\hline 8 & 1117 & 86.879 & Sharp & C-N stretch & Aliphatic amines \\
\hline 9 & 1024 & 20.675 & Very sharp & C-N stretch & Aliphatic amines \\
\hline 10 & 672 & 66.003 & Weak & C-Br stretch & Alkyl helides \\
\hline 11 & 657 & 63.189 & Weak & C-Br stretch & Alkyl helides \\
\hline
\end{tabular}

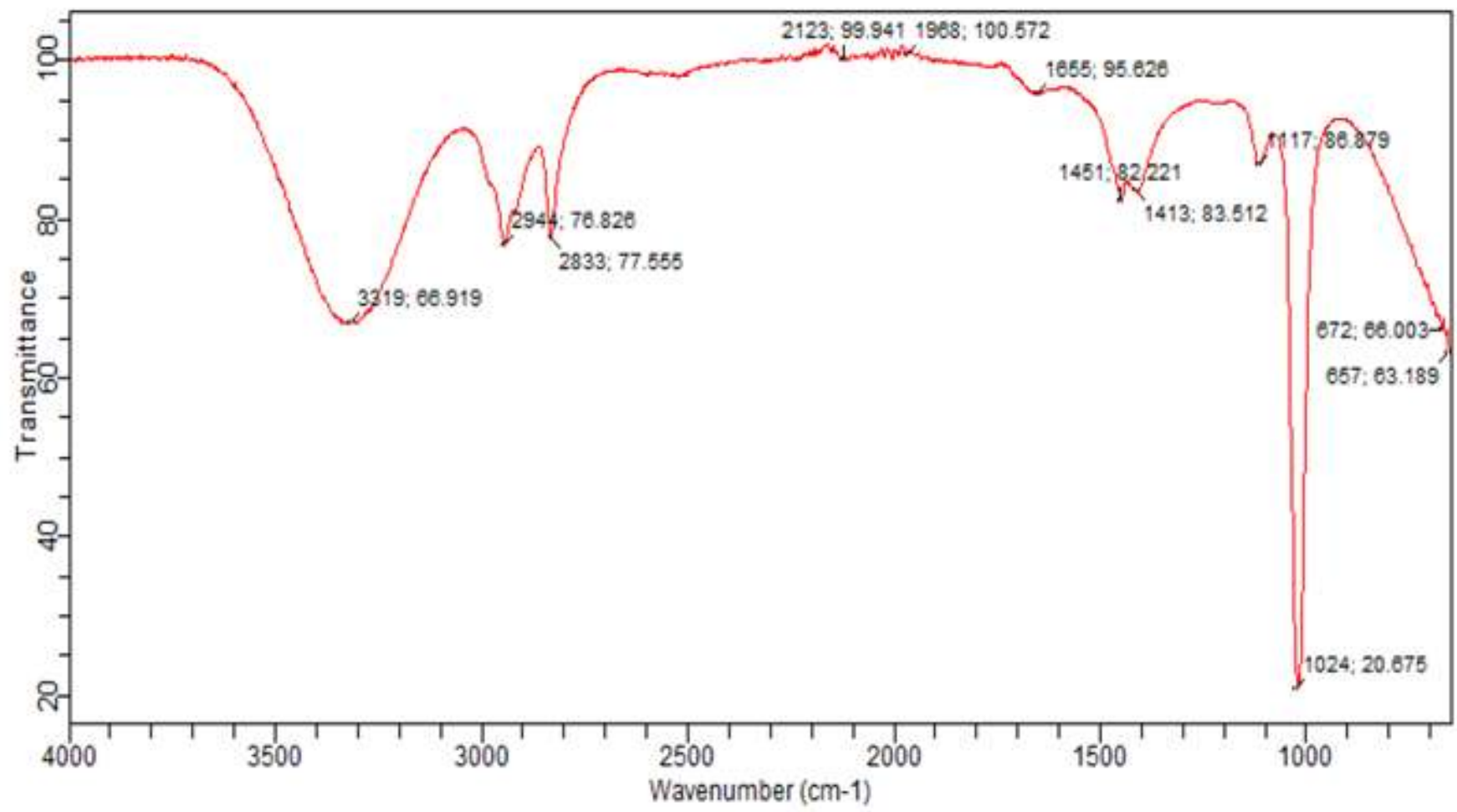

Figure 2: FTIR Spectra of the Crude Ethanolic Extract of Boswellia dalzielii

Also, the total ion chromatograms (TIC) of the extract, showing the GC-MS profile of the compounds identified were given in (Figure 3). The peaks in the chromatograms were integrated and were compared with the database of spectrum of known components stored in the GC-MS NIST library. On the other hand, Table 4 gave the detailed tabulation of GC-MS analysis of the extract in which 13 different constituents have been elucidated and effectively matched and identified. The major constituents observed were at peaks 4 (n-Hexadecanoic acid with peak area 23.54\%), Peak 7 (Oxacyclotetradecan-2-one with peak area $20.33 \%$ ), peak 8 (Pelargic acid with peak area 16.83\%), peak 12 (Methyl (Arachidic alcohol with peak area 13.51\%) and peak 9 (Ethyl steriate with peak area $10.05 \%$ ). While the rest constitute less than $16 \%$ composition by peak area. 




Figure 3: GC-MS Showing Total Ion Chromatogram (TIC) of Ethanolic Extract of the Stem Bark of Boswellia dalzielii

Table 4: Phytochemical Components Identified form the Crude Ethanolic Extract of the Stem Bark of Boswellia dalzialii by GC-MS Analysis

\begin{tabular}{|c|c|c|c|c|}
\hline $\begin{array}{c}\text { Peak } \\
\text { Number }\end{array}$ & $\begin{array}{c}\text { Retention } \\
\text { Time (minutes) }\end{array}$ & $\begin{array}{c}\text { \% Composition } \\
\text { by Area }\end{array}$ & $\begin{array}{l}\text { Matched compound } \\
\text { IUPAC Name }\end{array}$ & Chemical Structure \\
\hline 1 & 9.624 & 0.20 & 1-Dodecene & \\
\hline 2 & 11.721 & 0.93 & 3,5-Di-tert-butylphenol & \\
\hline 3 & 12.30 & 0.25 & 1-Hexadecene & \\
\hline 4 & 18.069 & 23.54 & n-Hexadecanoic acid (Palmitic acid) & \\
\hline 5 & 18.370 & 2.43 & Ethyl docosanoate & in. \\
\hline 6 & 20.100 & 0.77 & $\begin{array}{l}\text { 9,12-Octadecadienoyl chloride(Linoleic acid } \\
\text { Chloride) }\end{array}$ & \\
\hline 7 & 21.148 & 20.33 & Oxacyclotetradecan-2-one & \\
\hline 8 & 21.362 & 16.83 & n-Nonanoic acid (Pelargic acid) & \\
\hline 9 & 21.850 & 10.05 & Ethyl- octadecanoate (Ethyl stearate) & \\
\hline 10 & 23.979 & 3.97 & 1,E-11,Z-13-Octadecatriene & \\
\hline 11 & 24.358 & 4.13 & $\begin{array}{l}\text { 3,5,6,7,8,8a-hexahydro-4,8a-dimethyl-6-(1- } \\
\text { methylethenyl)- } 2(1 \mathrm{H}) \text { Naphthalenone }\end{array}$ & \\
\hline 12 & 25.574 & 13.51 & n-Eicosanol (Arachidic alcohol) & \\
\hline 13 & 25.982 & 3.03 & Sulfurous acid, 2-propyl tetradecyl ester & \\
\hline
\end{tabular}

Volume 6 Issue 12, December 2017

\author{
www.ijsr.net
}

Licensed Under Creative Commons Attribution CC BY 


\section{International Journal of Science and Research (IJSR) \\ ISSN (Online): 2319-7064}

Index Copernicus Value (2016): 79.57 | Impact Factor (2015): 6.391

\section{B. Antimicrobial activity}

The result of the antimicrobial activity of the extract showing the means and standard error means of the diameters of zones of inhibition produced by the various concentrations of the extract as well as the MIC and MBC/MFC values of the extract for each of the organisms are shown in Table 5. The result showed that the extract is active against all the test isolates with higher zones of inhibition of $21 \pm 0.00 \mathrm{~mm}$ for $C$. albicans and $S$. typhi, $20 \pm 0.80 \mathrm{~mm}$ for $S$. aureus, and $19 \pm 0.50 \mathrm{~mm}$ for $K$. pneumoniae, $18 \pm 0.80 \mathrm{~mm}$ for $E$. coli and $18 \pm 0.80 \mathrm{~mm}$ for $P$. aeruginosa at $50 \mathrm{mg} / \mathrm{ml}$ concentration each. Resistance was only observed at $2.5 \mathrm{mg} / \mathrm{ml}$ concentration for $S$. pyogenes Similarly, lowest MIC values of $3.12 \mathrm{mg} / \mathrm{ml}$ were obtained for C. albicans and S. typhi, $6.25 \mathrm{mg} / \mathrm{ml}$ for $S$. aureus, $12.5 \mathrm{mg} / \mathrm{ml}$ for $K$. Pneumoniae, E. faecalis and P. mirabilis, $25 \mathrm{mg} / \mathrm{ml}$ for $E$. coli and $S$. pyogenes and the highest MIC of $50 \mathrm{mg} / \mathrm{ml}$ for $P$. aeruginosa. The MBC/MFC values did not exceed the corresponding MIC values by more than a factor of 2 (Table 5).

Table 5: Antimicrobial Activity of the Crude Petroleum Ether Extract of the Stem Bark of Boswellia dazielii

\begin{tabular}{|c|c|c|c|c|c|c|c|c|}
\hline \multirow{2}{*}{ S/N } & Test Organisms & \multicolumn{2}{|c|}{$\begin{array}{c}\text { Means and Standard Error Means of the Diameters of the Zones of Inhibition } \\
\text { Produced by the Various Concentrations of the Extract against the test } \\
\text { Organisms (mm) }\end{array}$} & $\begin{array}{c}\text { MIC } \\
(\mathrm{mg} / \mathrm{ml})\end{array}$ & $\begin{array}{c}\text { MBC/MFC } \\
(\mathrm{mg} / \mathrm{ml})\end{array}$ \\
\cline { 3 - 8 } & & $50 \mathrm{mg} / \mathrm{ml}$ & $25 \mathrm{mg} / \mathrm{ml}$ & $10 \mathrm{mg} / \mathrm{ml}$ & $5 \mathrm{mg} / \mathrm{ml}$ & $2.5 \mathrm{mg} / \mathrm{ml}$ & & \\
\hline 1 & S. aureus & $20 \pm 0.80$ & $16 \pm 0.20$ & $11 \pm 0.40$ & $7 \pm 0.80$ & $7 \pm 0.10$ & 6.25 & 12.5 \\
\hline 2 & E. faecalis & $15 \pm 0.30$ & $11 \pm 0.20$ & $9 \pm 0.72$ & $9 \pm 0.03$ & $8 \pm 0.11$ & 12.5 & 25 \\
\hline 3 & S. pyogenes & $15 \pm 0.20$ & $13 \pm 0.22$ & $10 \pm 0.50$ & $8 \pm 0.60$ & $6 \pm 0.00^{*}$ & 25 & 50 \\
\hline 4 & P. aeruginosa & $17 \pm 0.60$ & $9 \pm 0.78$ & $9 \pm 0.30$ & $7 \pm 0.09$ & $7 \pm 0.10$ & 50 & 100 \\
\hline 5 & K. pneumoniae & $19 \pm 0.50$ & $14 \pm 0.30$ & $10 \pm 0.04$ & $9 \pm 0.41$ & $8 \pm 0.70$ & 12.5 & 25 \\
\hline 6 & E. coli & $18 \pm 0.80$ & $17 \pm 0.03$ & $11 \pm 0.60$ & $10 \pm 0.35$ & $9 \pm 0.10$ & 25 & 50 \\
\hline 7 & S. typhi & $21 \pm 0.00$ & $18 \pm 0.40$ & $15 \pm 0.06$ & $9 \pm 0.20$ & $8 \pm 0.70$ & 3.12 & 12.5 \\
\hline 8 & P. mirabilis & $16 \pm 0.20$ & $14 \pm 0.80$ & $10 \pm 0.21$ & $7 \pm 0.50$ & $7 \pm 0.80$ & 12.5 & 25 \\
\hline 9 & C. albicans & $21 \pm 0.00$ & $17 \pm 0.03$ & $11 \pm 0.20$ & $8 \pm 0.10$ & $8 \pm 0.53$ & 3.12 & 12.5 \\
\hline
\end{tabular}

Values are means plus or minus standard error means obtained from 3 replicas

Key: * Indicates resistance.,

$\mathrm{MBC}=$ Minimum Bactericidal Concentration,
$\mathrm{MIC}=$ Minimum Inhibitory Concentration

MFC = Minimum Fungicidal Concentration

\section{Discussions}

Medicinal plants have been one of the major sources of natural chemotherapeutic agents due to their ability to synthesise and accumulate pharmacologically important secondary metabolites. According to Nandagopalan et al., (2015), knowledge of the chemical constituents of plants is desirable not only for the discovery of therapeutic agents, but also because such information may be of great value in disclosing new sources of economic phytochemical compounds for the synthesis of complex chemical substances and for discovering the actual significance of folkloric remedies. This study was conducted using advanced automated techniques (GC-MS, HPLC and FTIR) to determine the full identity of the phytochemical compounds present in the ethanolic stem bark extract of $B$. dalzielii. In addition, the in vitro antimicrobial activity of the extract on some common human pathogenic microorganisms was also determined.

Findings from this study showed that the stem bark of $B$. dalzielii is very rich in pharmacologically active phytocomponents among which are n-Hexadecanoic acid palmitic acid (peak area 23.5\%) which is reported to have an antioxidant, hypocholesterolemic, nematicide, pesticide, lubricant activities and hemolytic 5-alpha is a reductase inhibitors (Sermakkani et.al. 2012); 9,12-Octadecadienoyl chloride(Linoleic acid Chloride) which possesses antiinflammatory, insectifuge, hypocholesterolemic, cancer preventive, nematicide, hepatoprotective, antihistaminic, antieczemic, antiacne, 5-alpha reductase inhibitor, antiandrogenic, antiarthritic and anticoronary properties (Sermakkani et.al. 2012) and n-Eicosanol -Arachidic alcohol (peak area $13.51 \%$ ) which has antimicrobial activity. This finding explains the observed antimicrobial activities of the extract in this study and also corroborates the findings of reported of Alemika and Oluwole, (1991), Adelakun et al, (2001) and Etuk et al., (2006) who reported that the stem bark of $B$. dalzielii has strong anti-oxidant and antimicrobial activities and contain many pharmacologically active secondary metabolites such as saponins, tannins, flavonoids, cardiac glycosides, steroids and terpenes.

In addition, the extract also contain Oxacyclotetradecan-2one (peak area 20.33\%) which is the second most abundant phytocomponents identified in the extract. This compound is an important component of Erythromycin and Roxithromycin antibiotics. This further supports the strong antimicrobial activity exhibited by the stem bark of $B$. dalzielii.

However, it should be noted that, although the extract contained many medicinally important constituents, it contain some toxic compounds such as n-nonanoic acidPelargic acid (peak area 16.83\%) which was reported as being highly corrosive disinfectant and algaecide that is commonly used in conjunction with glyphosate, a nonselective herbicide, for a quick burn-down effect in the control of weeds in turf grass and in the preparation of plasticizers and lacquers (Regulation (EU) $n^{\circ} 528,2012$ ). It also contained Ethyl steriate (peak area 10.05\%) which was reported to cause skin, eye, respiratory and digestive tract irritations (MSDS, 1998). The presence of these toxic compounds corroborates the findings of Abdalazeez et al., (2013) that reported mild toxicity of aqueous stem bark extract of $B$. dalzielii. Further research is therefore needed to validate the safety of the stem bark of $B$. dalzielii for consumption.

On the other hand, the results of the antimicrobial activity, in this study, showed that the extract has broad spectrum of

\section{Volume 6 Issue 12, December 2017}




\section{International Journal of Science and Research (IJSR) \\ ISSN (Online): 2319-7064}

Index Copernicus Value (2016): 79.57 | Impact Factor (2015): 6.391

activity against the gram negative and gram positive bacteria as well as the fungal isolates used in the study. The result therefore, corroborates the findings of Alemika and Oluwole, (1991); Duwiejua et al., (1993); Adelakun et al., (2001) and Abdulazeez et al., (2013) who reported that $B$. dalzielii stem bark has broad spectrum of antimicrobial activity.

However, Pseudomonas aeruginosa appeared to have the highest MIC $(50 \mathrm{mg} / \mathrm{ml})$ and MBC $(100 \mathrm{mg} / \mathrm{ml})$. This might not be unconnected with the fact that $P$. aeruginosa is one of the notable drug resistant organisms due to combination of many factors such as low permeability of its cell wall, its genetic capacity to express a wide repertoire of resistance mechanisms, mutation in chromosomal genes which regulate resistance genes, or acquisition of additional resistance genes from other organisms via plasmids, transposons and bacteriophages as reported by Lambert, (2002).

Furthermore, the fact that none of the organisms used in this study was completely resistant to the extract implies that, the stem bark of $B$. dalzielii can be used in the treatment of many infections caused by the organisms especially those caused by $S$. typhi and $C$. albicans as they appeared to be the most susceptible organisms with MIC of $3.12 \mathrm{mg} / \mathrm{ml}$ each.

\section{Conclusion}

The crude ethanolic extract of stem bark of Boswellia dalzielii has strong antibacterial and antifungal activity and contained many antimicrobially active compounds. However, further research is needed to separate these bioactive compounds from the potentially toxic components of the stem bark identified in this study. In addition, adequate toxicological data is needed to validate the safety of the stem bark of this plant for consumption purpose. Furthermore, metabolomic study of the extract is also recommended in future to identify the metabolites present in the active compounds identified in this research as well as their systemic functions and effects on human consumption.

\section{Acknowledgement}

We acknowledge the management of Umaru Musa Yar'adua University for their support and TETFUND Nigeria for funding the research.

\section{Conflict of Interest}

We declare none

\section{References}

[1] Abdulazeez A. T, Kabele-Toge B., Lawal M. and Abubakar M. G. (2013). Phytochemical, Antibacterial and Toxicological Studies of Aqueous Stem Bark Extract of Boswellia dalzielli. African Journal of Pharmaceutical Research \& Development, Vol. 5 No.1 pp.61-67.

[2] Adelakun E.A., Finbar E.A.V., Agina S.E. and Makinde A.A. (2001): Antimicrobial activity of Boswellia dalzielii stem bark; Fitoterapia 72(7), 822-824.
[3] Ahmed Salih Sahib, Imad Hashim Mohammed, Saba Jasim Hamdan. (2012). Use of aqueous extract of corn silk in the treatment of urinary tract infection. Journal of Intercultural Ethnopharmacology;1(2):93-96. Available at www.scopemed.org

[4] Alemika T.O.E. and Oluwole F.S. (1991): An investigation of the potentials of Boswellia dalzielii and Commiphora kerstingii in the treatment of peptic ulcer; West African Journal of Pharmacology \& Drug Research., 9/10, 91-94.

[5] BBC News. Antibiotic resistance rise continues. 2014. Available at: http://www.bbc.co.uk/news/health29553435 (accessed 19.03.2015).

[6] Cabello F. Heavy use of prophylactic antibiotics in aquaculture: A growing problem for human and animal health and for the environment. Environ. Microbiol. 2006;8:1137-1144. doi: 10.1111/j.14622920.2006.01054.x.

[7] Centers for Disease Control and Prevention (2013). Meeting the Challenges of Drug-Resistant Diseases in Developing CountriesCommittee on Foreign Affairs Subcommittee on Africa, Global Health, Human Rights, and International Organizations, United States House of Representatives. April 23, 2013.

[8] CILS and Antimicrobial SusceptibilityTesting. (1998). Performance Standards for Antimicrobial Susceptibility Testing. In Blood Safety and Clinical Technology Guidelines on Standard Operating Procedures for Microbiology. Eight Informational Supplement. M100S8, 18 (1), CILS Pennsylvania, USA.

[9] Da Costa, P. M., Loureiro, L., \& Matos, A. J. F. (2013). Transfer of Multidrug-Resistant Bacteria between Intermingled Ecological Niches: The Interface between Humans, Animals and the Environment. International Journal of Environmental Research and Public Health, 10(1), 278-294. http://doi.org/10.3390/ijerph10010278

[10] Duwiejua M., Zeitlin I.J., Waterman P.G., Chapman J., Mhango G.J. and Provan G.J. (1993): Antiinflammatory activity of resins from some of the plant family Burseraceae; Plant Medicine., 59(1), 12-16.

[11]Etuk E U, Agaie B M, Onyeyili P A, Ottah C U.(2006). Toxicological studies of aqueous stem bark extract of Boswellia dalzielii in albino rats. Indian $\mathbf{J}$ Pharmacolology;38:359-60. Available from: http://www.ijponline.com/text.asp?2006/38/5/359/27707

[12]Franco, B. E., Altagracia Martínez, M., Sánchez Rodríguez, M. A., \& Wertheimer, A. I. (2009). The determinants of the antibiotic resistance process. Infection and Drug Resistance, 2, 1-11.

[13] Hugo and Russell (2004). Pharmaceutical microbiology, $8^{\text {th }}$ edi, edited by Stephen P. D., Norman A. H and Sean P. G., 11(187-201).

[14] Händel N, Otte S, Jonker M, Brul S, ter Kuile BH (2015) Factors That Affect Transfer of the IncI1 $\beta$ Lactam Resistance Plasmid pESBL-283 between E. coli Strains. PLoS ONE 10(4): e0123039. https://doi.org/10.1371/journal.pone.0123039

[15]Hsiao-Han Chang, Ted Cohen, Yonatan H. Grad , William P. Hanage, Thomas F. O'Brien and Marc Lipsitch. (2015). Origin and Proliferation of MultipleDrug Resistance in Bacterial Pathogens. Microbiology and Molecular Biology Rev. vol. 79 no. 1 101-116 


\section{International Journal of Science and Research (IJSR) \\ ISSN (Online): 2319-7064 \\ Index Copernicus Value (2016): 79.57 | Impact Factor (2015): 6.391}

[16]Lambert P.A. (2002).Mechanisms of antibiotic resistance in Pseudomonas aeruginosa; Section of Paediatrics \& Child Health. Journal of research in soc mededicine ;95(suppl. 41):22-26

[17] Material Safety Data Sheet (1998). Ethyl stearate, 99\%, ACC\# 05986. Revised on 9/26/2007, assessed on 17/7/2016.

[18] MFMER (Mayo Foundation for Medical Education and Research). (2014). Antibiotics: Misuse puts you and others at risk. Available at https://www.mayoclinic.org/healthy-lifestyle/consumerhealth/in-depth/antibiotics/art-20045720. (Accessed 16/12/2017).

[19] Murugan, K., Saravanababu, S., Arnachalam, M. (2007). Screening of tannin acyl hydrolase (E. C. 3.1.1.20) producing tannery effluent fungal isolates using simple agar plate and smF process. Bioresources and Technolology, 98: 946949.

[20] Nandagopalan, V., Gritto, M. J., \& Doss, A. (2015). GC-MS analysis of bioactive components of the methanol extract of Hibiscus tiliaceus Linn . Asian Journal of Plant Science and Research, 5(3), 6-10. Retrieved from www.pelagiaresearchlibrary.com

[21] Nemesis Bioscience News (2017). Available at http://www.nemesisbio.com/the-problem/ (accessed 1612-2017)

[22] Rantala M., Hölsö K., Lillas A., Huovinen P., Kaartinen L. Survey of condition-based prescribing of antimicrobial drugs for dogs at a veterinary teaching hospital. Vet. Rec. 2004;155:259-262. doi: 10.1136/vr.155.9.259.

[23] Rawat, Vinita and Umesh Paul, Priyanka. (2010). Antibiotic resistance pattern of urinary tract isolates of Escherichia coli from Kumaun region. The Journal of communicable diseases. 42. 63-6

[24] Regulation (EU) $n^{\circ} 528 / 2012$ concerning the making available on the market and use of biocidal products. Nonanoic acid Product-type 2 Assessment report finalised on 27/09/2013, assessed on 27/7/2016

[25] Salisu, B., Magashi, A. M., \& Mohammed, A. (2017). Determination of Phytochemicals and Antimicrobial Activity of Aqueous Stem Bark Extract of Boswellia dalzielii against Some Common Pathogenic Microorganisms. UMYU Journal of Microbiology Research, 2(1), 238-246. Retrieved from www.umyu.edu.ng

[26] Sande-Bruinsma N., Grundmann H., Verloo D., Tiemersma E., Monen J., Goossens H., Ferech M. Antimicrobial drug use and resistance in Europe. Emerg. Infect. Dis. 2008;11:1722-1730.

[27] Schwarz S., Kehrenberg C., Walsh T. Use of antimicrobial agents in veterinary medicine and food animal production. Int. J. Antimicrob. Agents. 2001;17:431-437. doi: 10.1016/S0924-8579(01)002977.

[28] Sermakkani M \& Thangapandian V. ( 2012). GCMS analysis of Cassia italic leaf methanol extract. Asian journal of pharmaceutical and clinical research .vol 5.

[29] Shalini., Joshi, MC., Rashid, MK., and Joshi, HS.2011. Study of Antibiotic Sensitivity Pattern In Urinary Tract Infection At A Tertiary Hospital. NJIRM; Vol. 2(3): 43-46.
[30] Sunday Ene-Ojo, Atawodi Gboyega and Suleiman Onaolapo (2010). Comparative in vitro antioxidant potential of different parts of Ipomoea asarifolia, Roemer \& Schultes, Guiera senegalensis, J. F. Gmel and Anisopus mannii N. E. Brown. Braz. J. Pharm. Sci. vol.46 no.2 São Paulo Apr./June 2010 ,http://dx.doi.org/10.1590/S1984-82502010000200011

[31] Susanne Schjørring and Karen A. Krogfelt, "Assessment of Bacterial Antibiotic Resistance Transfer in the Gut," International Journal of Microbiology, vol. 2011, Article ID 312956, 10 pages, 2011. doi:10.1155/2011/312956

Volume 6 Issue 12, December 2017 www.ijsr.net 